\title{
BALANÇO HÍDRICO DO CULTIVO DA NOGUEIRA PECÃ NOS ANOS- PADRÃO HABITUAL, CHUVOSO E SECO PARA O RIO GRANDE DO SUL
}

\author{
ROVANI, Franciele Francisca Marmentini - franciele.rovani@yahoo.com.br \\ Universidade Federal de Santa Maria / UFSM \\ WOLLMANN, Cássio Arthur - cassio_geo@yahoo.com.br \\ Universidade Federal de Santa Maria / UFSM
}

\begin{abstract}
RESUMO: O objetivo desta pesquisa consistiu em realizar a análise do balanço hídrico do cultivo da nogueira pecã (Carya illinoinensis) nos anos-padrão habitual, chuvoso e seco no Rio Grande do Sul. Para tanto, coletou-se dados de precipitação pluviométrica e temperatura média do ar junto às 23 estações convencionais do Instituto Nacional de Meteorologia localizadas no Estado, no período de 1998 a 2013. Os dados foram organizados em planilhas do Microsoft Excel em escala diária e mensal. Realizou-se a identificação dos anos-padrão habitual, seco e chuvoso e a elaboração do balanço hídrico do cultivo para oito estações meteorológicas. Como resultado destaca-se o ano de 2013, o ano-padrão habitual $(1.657 \mathrm{~mm})$, o ano de 2002 , chuvoso $(2.201 \mathrm{~mm})$ e o ano de 2004, ano seco (1.307 mm). Na análise do balanço hídrico, o ano de 2002, apresentou na maioria das estações excesso hídrico nos meses de setembro a dezembro, período de floração e formação dos frutos. As maiores ocorrências de déficit hídrico foram no ano de 2004, no crescimento das nozes e na colheita, isto é, de janeiro a abril. No ano de 2013, constatou-se períodos de excedente hídrico alternados de déficit para todas as estações em análise. Desta forma, pode-se inferir que o cultivo da nogueira pecã é recomendado para o Estado, mas antes da implantação de um pomar é necessário avaliar as condições edafoclimáticas específicas do local.
\end{abstract}

PALAVRAS-CHAVES: Climatologia Agrícola; Precipitação pluviométrica; Carya illinoinensis.

\section{HIDRICAL BALANCE IN THE CULTIVATION OF PECAN NUTS IN THE USUAL PATTERN YEARS, RAINY AND DRY FOR RIO GRANDE DO SUL}

ABSTRACT: The objective of this research is to accomplish the analysis of water balance in the cultivation of pecan nuts (Carya illinoinensis) in the years of usual pattern, rainy and dry in Rio Grande do Sul. However, the dada of rainfall precipitation and the air temperature in the 23 weather station from National Institute of Meteorology, located in the state were collected, in the period from 1998 to 2013. The dada were organized in Microsoft Excel in daily and monthly scales. The identification of the usual pattern wet and dry was accomplished and the preparation of the water balance of cultivation for weather station. As a result, emphasize the 2013-year the usual pattern $(1.657 \mathrm{~mm})$, 2002 year, rainy $(2.201 \mathrm{~mm})$ and 2004 , dry year $(1.307 \mathrm{~mm})$. In the analysis of the water balance 2002, presented in most station excess water from September to December, flowering and fruit formation season. The greatest occurrences of water deficit were in 2004, in the growing of pecan nuts and harvesting, that is, from January to April. In 2013, periods of water excess alternated with deficit were observed in all weather station analyzed. This way, we can infer that pecan nut cultivations are recommended in the state but is necessary evaluation of the weather condition before implantation of orchards in the place.

KEYWORDS: Agricultural Climatology; Rainfall; Carya illinoinensis.

BALANCE HÍDRICO DEL CULTIVO DEL NOGAL PECANERO EM LOS AÑOS HABITUAL, LLUVOSO Y SECO PARA EL RIO GRANDE DO SUL

RESUMEN: El objetivo de esta investigación consistió en realizar el análisis del balance hídrico del cultivo del nogal pecanero (Carya illinoinensis) en los años habitual, lluvioso y seco en Rio Grande do Sul. Se recogieron datos de precipitación pluviométrica y 
temperatura media del aire junto a las 23 estaciones convencionales del Instituto Nacional de Meteorología ubicadas en el Estado en el período 1998 a 2013. Los datos se organizaron en hojas de cálculo de Microsoft Excel a escala diaria y mensual. Se realizó la identificación de los años habitual, seco y lluvioso y la elaboración del balance hídrico del cultivo para ocho estaciones meteorológicas. Como resultado se destaca el año de 2013, el año habitual (1.657 mm), el año 2002, lluvioso $(2.201 \mathrm{~mm}$ ) y el año 2004, año seco $(1.307 \mathrm{~mm})$. En el análisis del balance hídrico, el año 2002, presentó en la mayoría de las estaciones excedente hídrico en los meses de septiembre a diciembre, período de floración y formación de los frutos. Las mayores ocurrencias de déficit hídrico fueran en el año 2004, en el crecimiento de las nueces y en la cosecha, es decir, de enero a abril. En el año 2013, se registraron períodos de excedente hídrico alternados de déficit para todas las estaciones en análisis. De esta forma, se puede inferir que el cultivo del nogal pecanero es recomendado para el Estado, pero antes de la implantación de un huerto es necesario evaluar las condiciones edafoclimáticas específicas del local.

PALABRAS CLAVE: Climatología Agrícola; Precipitación pluviométrica; Carya illinoinensis.

\section{INTRODUÇÃO}

Um dos elementos indispensáveis na vida dos seres vivos é a água. Mota e Zahler (1994) salientam que a água constitui $90 \%$ da massa total do protoplasma, participa de inúmeras reações químicas na matéria viva, sendo o solvente que transporta os materiais no floema e no xilema. Além disso, é uma fonte de íons para redução do $\mathrm{CO}_{2}$ na fotossíntese e para as reações de luz.

A água é fundamental para a produção agrícola. A principal fonte para as culturas é a chuva e o seu principal reservatório é o solo. As principais perdas estão ligadas diretamente pela transpiração dos vegetais e pela evaporação da água da chuva retida no solo. Desta forma, quando a água do solo não é suficiente para suprir as necessidades dos vegetais e não há meios para supri-la devido à falta de chuva, ocorrem as secas ou as estiagens (MOTA; ZAHLER, 1994).

De acordo com Pereira, Angelocci e Sentelhas (2002) a disponibilidade hídrica pode ser quantificada pelo balanço hídrico climatológico, no qual fica evidenciada a flutuação temporal de períodos com excedente hídrico (úmidos) e com deficiência hídrica (períodos secos). O balanço hídrico da cultura fornece estimativas da evapotranspiração real (ETR), da deficiência hídrica (DEF), do excedente hídrico (EXC) e do armazenamento de água no solo (ARM) levando em consideração a capacidade de armazenamento de água no solo (CAD), a precipitação pluviométrica e a demanda atmosférica, simbolizada pela evapotranspiração potencial (ETP), bem como do coeficiente da cultura (Kc).

O balanço hídrico, portanto, é a contabilização da água no solo e pode ser representado pelas entradas (precipitação, irrigação, orvalho, escorrimento superficial, drenagem lateral e ascensão capilar) e pelas saídas (evapotranspiração, escorrimento superficial, drenagem lateral e profunda) dos fluxos da área vegetada (PEREIRA; ANGELOCCI; SENTELHAS, 2002). Segundo os autores (p. 248), "a chuva e o orvalho dependem do clima da região, enquanto que as demais entradas dependem do tipo de solo e de relevo da região".

Nos estudos baseados em balanços hídricos diários e considerando a evapotranspiração de acordo com o estágio de desenvolvimento das diversas culturas é possível identificar informações quantitativas sobre probabilidades de 
secas e necessidades de irrigação, afirmam os autores Mota e Zahler (1994). De acordo com Grageda et al. (2013) o uso da água pelos cultivos é orientado pela demanda de evaporação da atmosfera, que depende da radiação direta, velocidade do vento e umidade relativa, e pelas características das árvores do pomar, principalmente pela idade (capacidade de absorção do sistema radicular) e etapa de crescimento do cultivo (crescimento das raízes e principalmente pela área foliar). Sendo assim, o coeficiente da cultura alterasse ao longo da estação de crescimento em função do tempo e do grau de crescimento, conforme as mudanças no índice de área foliar do pomar (SAMMIS; MEXAL; MILLER, 2004).

Dentre os cultivos agrícolas, destaca-se o cultivo da nogueira pecã (Carya illinoinensis), pelo seu potencial de expansão no território brasileiro e a carência de estudos científicos que enfoquem seus requerimentos edafoclimáticos e mecanismos de adaptação climática. Este cultivo, além da produção de nozes com alto valor nutricional, possuiu valor econômico, industrial, agroflorestal e medicinal, conforme destacam Mohlenbrock (2003) e Madero, Frusso e Bruno (2012). A nogueira pecã é uma árvore que requer disponibilidade de água acima de $800 \mathrm{~mm}$ anuais (MADERO, FRUSSO; BRUNO, 2012). A falta de água poderá ser suprimida pelos sistemas de irrigação, porém o efeito da umidade excessiva no solo, só poderá ser minimizado com locais de drenagem adequadas, ou seja, em áreas de encostas do que em áreas planas (SPARKS, 2005).

As nogueiras apresentam um sistema radicular pivotante e radicelas que provocam a lenta capacidade de absorção da água. Valdez e Durón (2009) afirmam que a disponibilidade de água para um pomar de nozes é função da quantidade e da capacidade em que o solo armazena a água e para que as produções sejam sustentáveis através dos anos, deverá manter um nível adequado de água que permita a árvore abastecer suas estruturas de acordo com a demanda, segundo a etapa fenológica e o tamanho das árvores.

A deficiência hídrica ou a umidade excessiva influenciam também na produção de nozes da safra subsequente. Segundo Sparks (1997), o estresse hídrico no período de enchimento das nozes bem como no desenvolvimento da amêndoa possui um retorno induzido na floração do ano seguinte. Além disso, a umidade no solo do ano anterior afeta o número de nozes que serão produzidas, enquanto que a umidade no ano corrente afeta no tamanho das nozes e na qualidade da amêndoa (SPARKS, 1997). Desta forma, objetivou-se analisar o balanço hídrico para o cultivo da nogueira pecã em condições de anos-padrão habitual, chuvoso e seco para o estado do Rio Grande do Sul (RS).

\section{MATERIAL E MÉTODOS}

Para este estudo, coletou-se junto às 23 estações convencionais da rede do Instituto Nacional de Meteorologia (INMET) localizadas no Estado (Figura 1) os dados climáticos em escala diária da precipitação pluviométrica e na escala horária (12, 18 e 24 UTC - Tempo Universal Coordenado) da temperatura média. O recorte temporal foi de 15 anos, isto é, de 1998 a 2013, exceto o ano de 2001, pois apresentava inconsistência dos dados. 


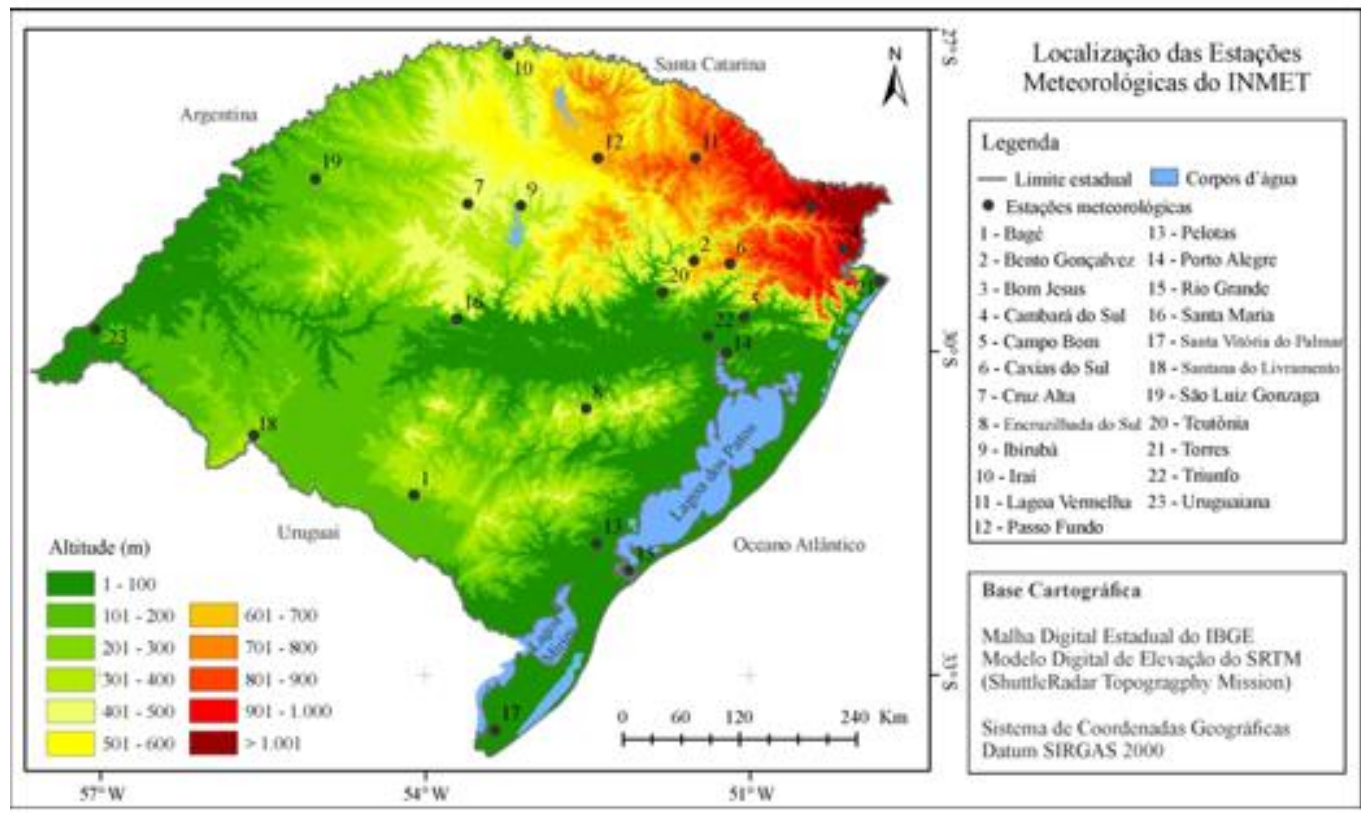

Figura 1 - Localização das estações meteorológicas no estado do Rio Grande do Sul.

Os dados foram organizados em planilhas do Microsoft Office Excel por variável climática no período histórico de todas as 23 estações meteorológicas. Realizou-se a média aritmética da temperatura média diária e posteriormente, a média mensal. Os dados de precipitação diários são computados como totais acumulados ao longo do dia. As medidas são realizadas às 12 UTC. Desta forma, o valor de precipitação associado para um dia correspondeu ao total de chuva acumulada desde às 12 UTC do dia anterior.

Para a organização mensal e anual da precipitação, buscou-se observar a recomendação da Organização Meteorológica Mundial (OMM, 1989). Para estes dados, a Organização orienta que sejam considerados apenas os períodos com dados completos, isto é, meses em que não se registrou a falta de dado em nenhum dia. No entanto, após observar os dados, definiu-se que sempre que um mês apresentasse até três dias sem registro dos dados, este não seria descartado. Entende-se que com este critério, o acumulado mensal não sofreria interferência significativa e devido à série temporal compreender 15 anos, elevar-se-ia o total de dados para análise.

Geralmente as séries temporais apresentam ocorrências extremas, isto é, valores muito altos ou muito baixos, por este fato utilizou-se os percentis ( $p 5$, p10, p90 e p95). Os percentis representam a percentagem de valores que estão antes ou depois de determinado dado, pela seguinte equação (1):

$$
\mathrm{L}=\mathrm{K} \cdot \mathrm{n} / 100
$$

Em que:

$L=$ posição do percentil desejado no conjunto ordenado

$\mathrm{K}=$ percentil desejado

$\mathrm{n}=$ número de valores 
Desta forma, o 10 percentil determina o $1 \%$ menor dos dados e 990 percentil determina o $99 \%$ maior dos dados. Os percentis mostram as excepcionalidades individuais do conjunto de dados, permitindo compreender a dinâmica dos dados no tempo e no espaço. Além disso, possibilitam entender a importância da latitude, do afastamento e da proximidade do mar, da altitude, a exposição à radiação solar e os fluxos de ar predominantes em cada posto meteorológico (MONTEIRO et al., 2012).

Com base nos dados de precipitação visou-se definir os anos-padrão chuvoso, seco e ano habitual, contribuindo para a análise global dos dados. Para a definição dos anos-padrão, utilizou-se a metodologia proposta por Sant'Anna Neto (1995), que utiliza o critério do desvio padrão em relação à média. De acordo com a técnica foi possível definir cinco classes para os anos em relação à precipitação: $\mathrm{S}=$ Ano Seco, TS = Ano Tendente a Seco, H = Ano Habitual, TC = Ano Tendente a Chuvoso e $\mathrm{C}=$ Ano Chuvoso (Figura 2).

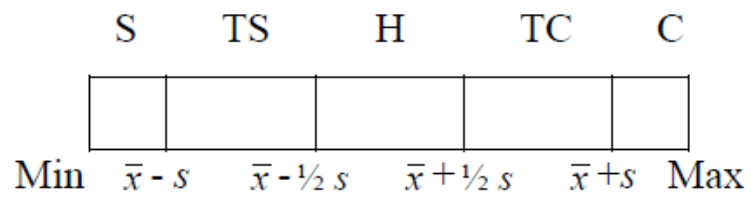

Figura 2 - Divisão de um ano-padrão em cinco classes usando a metodologia de um desvio padrão. Fonte: Silvestre, Sant'Anna Neto e Flores (2013).

Segundo a metodologia, e concordando com Moura e Zanella (2012) tem-se que: - ano chuvoso: ano com pluviosidade elevada (média mais um desvio-padrão); - ano tendente a chuvoso: ano com pluviosidade ligeiramente elevada, próximo a média mensal (média mais meio desvio-padrão); - ano habitual: ano com pluviosidade normal, cujo total pluvial situa-se dentro do desvio-padrão médio; - ano tendente a seco: ano com pluviosidade ligeiramente reduzida, próximo a média mensal (média menos meio desviopadrão); e - ano seco: ano com pluviosidade reduzida (média menos um desviopadrão).

O balanço hídrico foi elaborado com base nas rotinas em planilha do Microsoft Office Excel elaboradas por Rolim e Sentelhas (2002) seguindo a metodologia proposta por Thornthwaite e Mather (1955). Definiu-se como capacidade de armazenamento de água no solo (CAD) o valor de $100 \mathrm{~mm}$ conforme indicado por Gonçalves e Sentelhas (2008) para os estudos com culturas perenes.

Os valores de referência utilizados para o coeficiente da cultura (kc) foram obtidos com base no estudo desenvolvido por Dias (2007) para o período de setembro a maio, excetuando-se o período de dormência da nogueira. Estes valores foram definidos para cultivos de nogueira pecã em pleno crescimento, em regiões com invernos frios e sem desenvolvimento da cobertura vegetal de gramíneas. Utilizou-se também, dados referentes à latitude das estações meteorológicas, temperatura média do ar e da precipitação pluviométrica mensal para os anos de análise.

Foram selecionadas oito estações meteorológicas para a elaboração do balanço hídrico da cultura, sendo: Bom Jesus, Caxias do Sul, Encruzilhada do 
Sul, Iraí, Passo Fundo, Santa Maria, Santa Vitória do Palmar e Uruguaiana. O critério de escolha baseou-se na distribuição espacial das estações e nas regiões produtoras de nogueira pecã. O balanço hídrico foi elaborado em três anos distintos: ano chuvoso (2002), ano seco (2004) e ano habitual (2013).

A análise da influência da precipitação levou em consideração os estágios fenológicos da nogueira pecã que compreendem três períodos distintos: desenvolvimento vegetativo, desenvolvimento reprodutivo e senescência (FRUSSO, 2007). O estágio vegetativo, ocorre desde o final do mês de maio até meados de novembro, culminando com a brotação das folhas; o desenvolvimento reprodutivo compreende os períodos de floração, formação de frutos e maturação, transcorrendo desde os meses de outubro até abril e o estágio de senescência compreende o amarelecimento e caída das folhas durante os meses de maio e em junho (FRUSSO, 2007; MADERO; FRUSSO; CASAUBON, 2007).

\section{RESULTADOS E DISCUSSÃO}

A variação espacial da chuva no Estado sofre, em parte, a influência do relevo, uma vez que possui a Serra Geral no seu setor central, com alinhamento perpendicular à direção geral do deslocamento das frentes polares, e, no litoral norte, alinhada no sentido N-S, cujos ventos de leste e nordeste podem produzir aumento das chuvas, conforme destacado por Sartori (2003). Além disso, a autora enfatiza que a variabilidade temporo-espacial das precipitações, resultando em episódios de longas estiagens ou enchentes, pode ocorrer em qualquer época do ano e remetem às alterações na habitualidade da circulação atmosférica nas escalas regional e zonal, em parte provocadas pelos fenômenos El Niño e La Niña (SARTORI, 1993; 2003).

A precipitação pluviométrica média no Rio Grande do Sul é $1.651 \mathrm{~mm}$ anuais e variou de $1.200 \mathrm{~mm}$ a $2.000 \mathrm{~mm}$, valores estes, similares ao encontrado por Alvares et al. (2013), no qual destaca variação de 1.000 a 2.200 $\mathrm{mm}$ anuais no RS. Os meses mais chuvosos, de acordo com a frequência, são setembro e outubro, na maior parte do Estado, dado também comprovado por Sartori (2003), e o mês de maio é tido como o menos chuvoso. Os menores registros $(1.200 \mathrm{~mm}$ a $1.400 \mathrm{~mm}$ ) ocorreram nas regiões de Santa Vitória do Palmar e Rio Grande, no extremo sul. A porção norte do Estado, mais chuvosa, apresentou média pluviométrica entre 1.900 a $2.000, \mathrm{~mm}$ que compreende as regiões de Iraí, Passo Fundo, São Luiz Gonzaga e Cruz Alta. A região central do Estado, que abrange Santa Maria em direção a Bento Gonçalves, Lagoa Vermelha e Bom Jesus, apresentou média entre $1.700 \mathrm{~mm}$ e $1.800 \mathrm{~mm}$. Esses totais pluviométricos apontam satisfação hídrica anual da nogueira, pois Sparks (2005) indica que as precipitações médias devem ser em torno de $1.000 \mathrm{~mm}$ a $1.300 \mathrm{~mm}$ e outros autores, tais como Peterson (1990), Sierra, López e Pérez (2007) sugerem precipitação mínima de $750 \mathrm{~mm}$ e máxima de $2.000 \mathrm{~mm}$ ao ano.

A média histórica anual da precipitação permite verificar os anos de maior ou menor precipitação no Estado e as suas influências na produtividade das culturas (Tabela 1). 
Tabela 1 - Média histórica anual da precipitação, mediana, desvio-padrão (S) e percentis (P) 5, 10, 90 e 95

Precipitação $(\mathbf{m m})$

\begin{tabular}{lccccccc} 
& Acumulado & Mediana & $S(\mathbf{m m})$ & P5 & P10 & P90 & P95 \\
\hline 1998 & 1959,0 & 1919,5 & 469,1 & 1272,7 & 1406,6 & 2469,1 & 2698,3 \\
1999 & 1404,0 & 1378,2 & 276,0 & 1020,5 & 1065,2 & 1789,1 & 1840,7 \\
2000 & 1770,6 & 1730,9 & 295,2 & 1324,8 & 1491,3 & 2111,9 & 2227,6 \\
2002 & 2200,9 & 2032,2 & 422,0 & 1733,8 & 1810,3 & 2677,9 & 2846,8 \\
2003 & 1760,3 & 1746,1 & 257,8 & 1413,5 & 1440,9 & 2102,9 & 2139,0 \\
2004 & 1306,8 & 1296,9 & 209,2 & 1070,1 & 1070,1 & 1503,9 & 1532,9 \\
2005 & 1601,0 & 1524,1 & 342,2 & 1181,6 & 1202,9 & 2072,4 & 2086,5 \\
2006 & 1320,7 & 1296,1 & 230,0 & 1035,8 & 1085,2 & 1588,4 & 1638,3 \\
2007 & 1773,0 & 1754,5 & 322,5 & 1333,5 & 1410,4 & 2166,7 & 2215,5 \\
2008 & 1479,8 & 1500,6 & 306,1 & 1074,4 & 1109,2 & 1845,4 & 1932,7 \\
2009 & 1893,5 & 1959,6 & 269,7 & 1456,0 & 1656,0 & 2168,0 & 2194,4 \\
2010 & 1640,4 & 1679,9 & 287,8 & 1216,1 & 1310,2 & 2026,5 & 2034,9 \\
2011 & 1612,8 & 1610,1 & 404,7 & 1071,2 & 1113,9 & 2112,6 & 2153,4 \\
2012 & 1385,5 & 1404,7 & 219,7 & 994,9 & 1055,6 & 1616,8 & 1654,2 \\
2013 & 1656,8 & 1675,8 & 277,7 & 1249,3 & 1307,7 & 1973,0 & 1994,7 \\
\hline
\end{tabular}

Ao observar o total acumulado anual da série histórica, verifica-se que o ano de 2002 apresentou a maior média histórica $(2.200,9 \mathrm{~mm})$, seguido do ano de 1998, com média de 1.959 mm. No período de 1997/1998 e em 2002/2003, destaca-se a ocorrência do fenômeno El Niño, de magnitude forte e moderada, respectivamente, o que pode ter sido o fator de maior influência para o aumento significativo dos totais pluviométricos. O ano de 2004 apresentou a menor média histórica $(1.306,8 \mathrm{~mm})$ seguido dos anos de $2006(1.320,7 \mathrm{~mm})$ e 2012 $(1.385,5 \mathrm{~mm})$. O ano de 2011 apresentou precipitação mediana $(1.610,1 \mathrm{~mm})$, próximo à média $(1.612,8 \mathrm{~mm})$ e o ano de 2002 destaca-se por apresentar a maior variação entre a média e a mediana $(168,7 \mathrm{~mm})$. O desvio padrão é elevado em decorrência da grande variabilidade dos dados. O ano de 1998 foi o de maior variabilidade $(469,1 \mathrm{~mm})$ e o ano de 2004, o de menor (209,2 mm).

Com relação aos percentis, notou-se que o menor percentil 5 corresponde ao ano de $2012(994,9 \mathrm{~mm})$, enquanto que o maior foi em 2002 $(1.733,8 \mathrm{~mm})$. No percentil 95 , verificou-se que o menor valor registrado foi em $2004(1.532,9 \mathrm{~mm})$ e o maior, em 2002 (2.846,8 mm). Destaca-se ainda que o ano de 2004 apresentou totais pluviométricos iguais nos percentil 5 e 10, apontando para a menor variabilidade entre os menores valores, apesar das chuvas apresentarem grande variação temporo-espacial na área de estudo.

Para identificar o ano-padrão mais seco e o mais chuvoso, bem como o ano habitual, utilizou-se a metodologia proposta por Sant'Anna Neto (1995), 
que usou o critério do desvio-padrão em relação à média. A partir dessa análise, obteve-se os valores de referência para a série histórica (Figura 3).

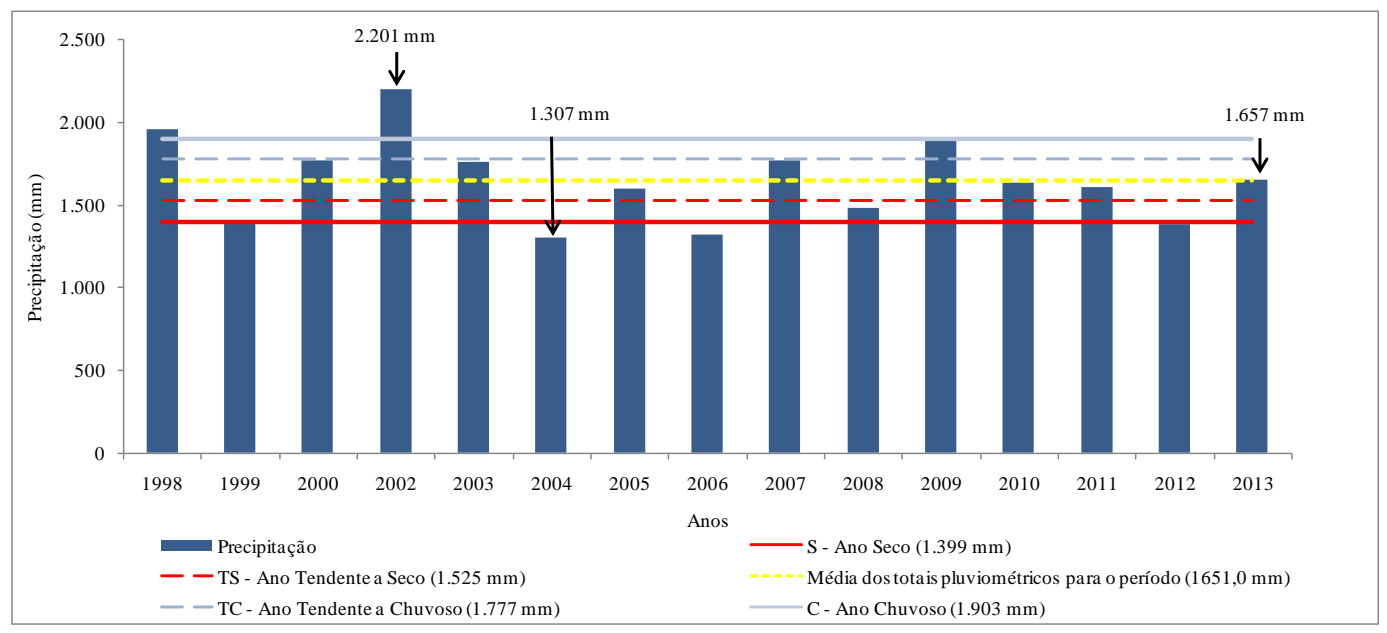

Figura 3 - Precipitação pluviométrica anual, ano tendente a seco, ano seco, ano tendente a chuvoso, ano chuvoso e média dos totais pluviométricos para o período de 1998 a 2013 no Rio Grande do Sul.

A média da precipitação pluviométrica da série histórica é de $1.651 \mathrm{~mm}$ e o desvio-padrão é de $252,1 \mathrm{~mm}$. O limite para identificar os anos secos foi de $1.399 \mathrm{~mm}$ (média menos um desvio-padrão), ou seja, os anos que apresentaram precipitações médias abaixo desse valor foram considerados secos, tais como 2004, 2006 e 2012. Os anos de 1999 e 2008 foram considerados tendentes a seco (média menos meio desvio-padrão) com limite de $1.525 \mathrm{~mm}$.

O ano mais chuvoso (média mais um desvio-padrão) foi identificado a partir de um limite mínimo de $1.903 \mathrm{~mm}$, resultando, nessa categoria, os anos de 1998 e 2002. O ano de 2009 foi identificado como tendente a chuvoso, com limite de $1.777 \mathrm{~mm}$. Os valores situados entre a média e mais ou menos meio desvio-padrão, ou seja, entre $1.525 \mathrm{~mm}$ a $1.777 \mathrm{~mm}$, definiram os anos considerados habituais. Obteve-se sete anos nessa categoria: 2000, 2003, 2005, 2007, 2010, 2011 e 2013. Assim, observando-se os anos que mais se destacaram como ano chuvoso, ano seco e habitual (mais próximo da média) verificou-se que o ano de $2002(2.201 \mathrm{~mm})$ pode ser considerado chuvoso, 0 ano de $2004(1.307 \mathrm{~mm})$, ano seco, e 2013 (1.657 mm), ano habitual.

De acordo com a série analisada, verifica-se que não há uma tendência de anos-padrão chuvosos ou secos, pois houve o predomínio da ocorrência dos anos considerados habituais. No entanto, no estudo realizado por Rossato (2011) ao analisar a série temporal que compreende o período de 1970 a 2007, a autora identificou pequena tendência de aumento da precipitação nas séries de dias de chuva, nenhuma tendência nas séries de total pluviométrico mensal e tendência positiva no somatório anual de precipitação.

A variação mensal da precipitação para os anos de 2002, 2004 e 2013, bem como a média mensal histórica, pode ser observada na figura 4. 


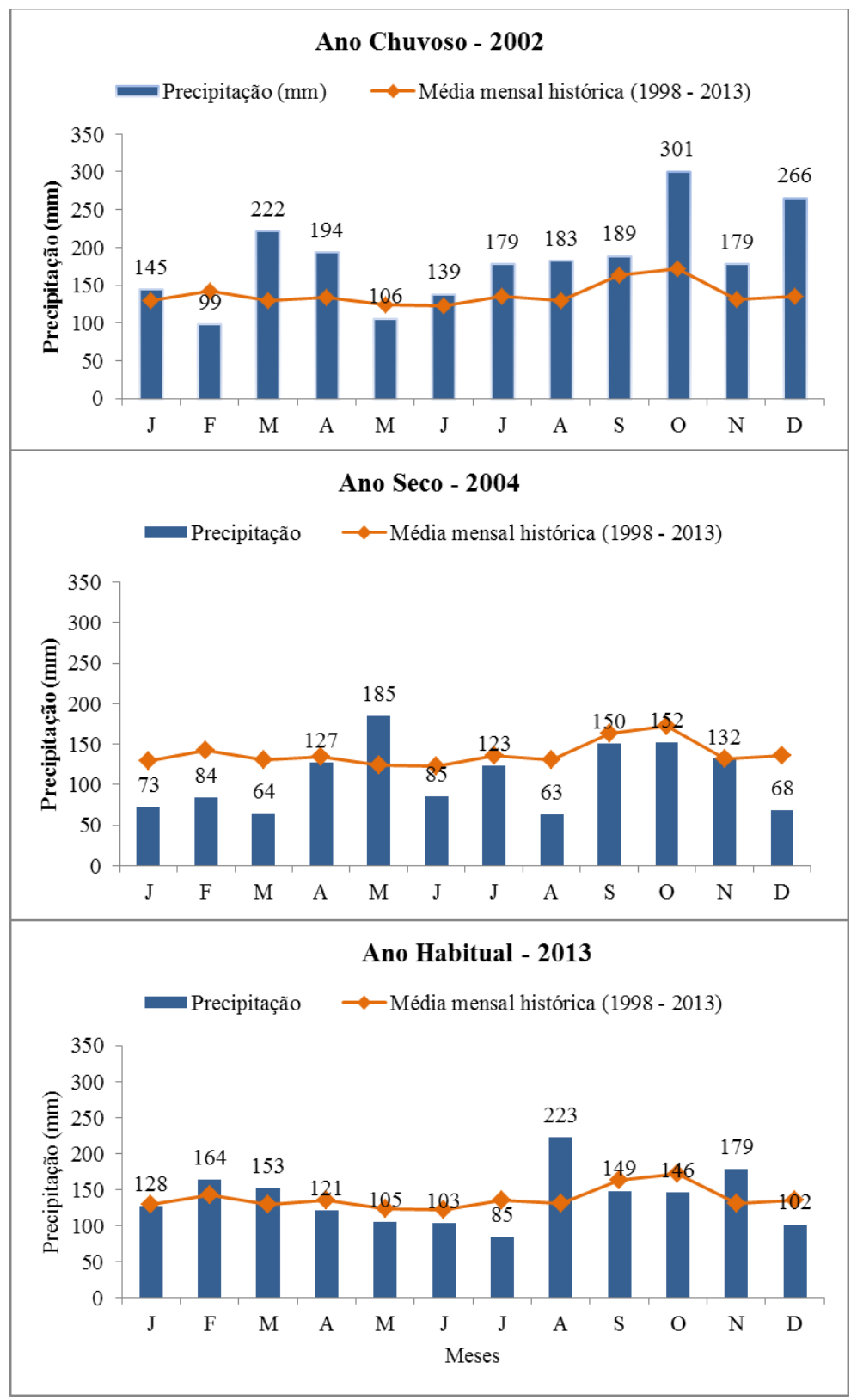

Figura 4 - Ano Chuvoso (2002), Ano Seco (2004) e Ano Habitual (2013) de acordo com a série histórica da precipitação pluviométrica no Rio Grande do Sul.

De acordo com a figura 4, o ano de 2002, considerado como chuvoso, apresentou somente os meses de fevereiro $(99 \mathrm{~mm})$ e maio $(106 \mathrm{~mm})$ abaixo da média histórica. No entanto, os meses de outubro (301 mm) e dezembro (266 mm) estiveram muito acima da média, ou seja, 129 e $131 \mathrm{~mm}$, respectivamente. $\mathrm{O}$ ano de 2004, considerado seco, apresentou somente os meses de maio (185 mm) e novembro (132 mm) acima da média. Os meses de 
janeiro $(73 \mathrm{~mm})$, fevereiro $(84 \mathrm{~mm})$, março $(64 \mathrm{~mm})$, junho $(85 \mathrm{~mm})$, agosto $(63 \mathrm{~mm})$ e dezembro $(68 \mathrm{~mm})$ registraram os menores valores em relação à média.

No ano de 2002, a precipitação elevada pode ser relacionada com a ocorrência do El Niño - Oscilação Sul (ENOS) no período de 2002/2003, comprovando-se com as chuvas abundantes na primavera. O ano de 2004 , mais especificamente o período de 2004/2005, registrou episódios dos dois fenômenos (El Niño e La Niña). A sua diferença entre o El Niño clássico é que o aquecimento do oceano Pacífico Equatorial não ocorre de forma simultânea e completa, e neste período, ficou agravado pelas águas mais frias do oceano Atlântico (PAIVA, 2015). Essa situação resultou em chuvas irregulares e uma forte estiagem no verão de 2005, causando prejuízos na produção agrícola, demonstrando que nem sempre o El Niño é sinônimo de excesso de chuva.

O ano chuvoso de 2002 pode ser considerado prejudicial ao cultivo da nogueira pecã, já que apresentou elevada precipitação, especialmente no mês de outubro e também novembro. Esses dois meses compreendem o período de floração e polinização da nogueira, que requer ação do vento para que ocorra a dispersão do pólen. Chuvas excessivas, de forma consecutiva, impedem o deslocamento do pólen e diminuem as chances de polinização. O ano de 2004, por sua vez, com os baixos índices de precipitação no período de desenvolvimento e formação das nozes (janeiro e fevereiro), pode influenciar significativamente no tamanho das nozes, na formação e no preenchimento da amêndoa, assim como na produtividade final.

O ano de 2013, considerado habitual, apresentou média anual de 1.657 $\mathrm{mm}$, muito próximo à média histórica de $1.651 \mathrm{~mm}$. Porém, ao observar os valores mensais, notam-se algumas variações interessantes. O mês de agosto (233 mm) apresentou o maior valor acima da média, ou seja, $93 \mathrm{~mm}$ a mais. Já o mês de julho $(85 \mathrm{~mm})$, destaca-se por apresentar o menor valor em relação à média, ou seja, $51 \mathrm{~mm}$ a menos que a média histórica. Os demais meses mantiveram-se com valores aproximados ao histórico registrado.

Segundo Sparks (1996; 2005), a baixa disponibilidade de água afeta o enchimento da amêndoa, principalmente em meados de janeiro e fevereiro, constituindo-se, assim, no maior período de estresse para a nogueira. Além disso, a falta de umidade suprime o crescimento dos frutos muito cedo, pelo menos três semanas após a polinização, influenciando também no período de expansão no mês de janeiro a meados de fevereiro (SPARKS, 2009).

No período da colheita das nozes, em abril e maio, na maioria das regiões analisadas, com exceção de Iraí, houve excedente hídrico. Em março, período em que as nozes já se encontram bem formadas, a região de Santa Vitória do Palmar apresentou o maior excedente hídrico com valor superior a $250 \mathrm{~mm}$. Essa região destaca-se pelos valores máximos e mínimos registrados, ou seja, precipitação de 473,5 mm em março e $42 \mathrm{~mm}$ em setembro.

O balanço hídrico sequencial da cultura para o ano chuvoso (2002) da série histórica, nas oito estações meteorológicas, pode ser observado na figura 5. 


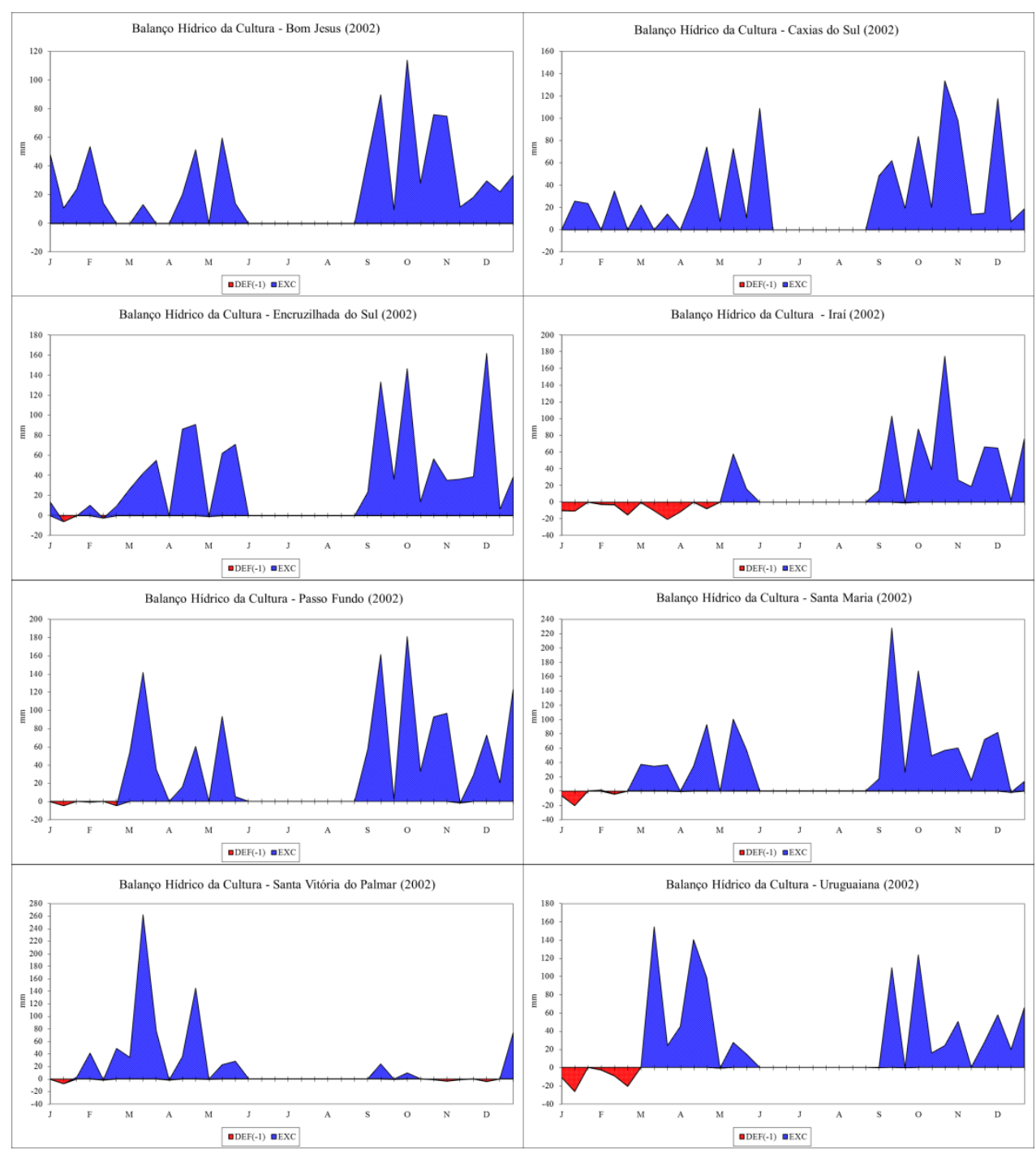

Figura 5 - Balanço hídrico da cultura para o ano-padrão chuvoso (2002) da série histórica em Bom Jesus, Caxias do Sul, Encruzilhada do Sul, Iraí e Passo Fundo, Santa Maria, Santa Vitória do Palmar e Uruguaiana.

O balanço hídrico sequencial do cultivo para o ano de 2002, ano chuvoso da série histórica, compreende dois ciclos do cultivo da nogueira, isto é, parte da safra de 2001/2002 e da safra 2002/2003, mas, ainda assim, possibilita identificar os períodos de excesso e déficit hídrico sob condições de elevada pluviosidade, nas principais fases fenológicas. De acordo com a figura 5, verificou-se que, na maioria dos locais em análise, houve alguns períodos de déficit hídrico, ou seja, falta de precipitação, mesmo diante de condições de um ano considerado chuvoso. A tabela 2 mostra os totais pluviométricos registrados nas oito estações meteorológicas, mensais e anual, para o ano de 2002. 
Tabela 2 - Precipitação pluviométrica do ano de 2002, mensal e total, em oito estações meteorológicas do Rio Grande do Sul.

\begin{tabular}{|c|c|c|c|c|c|c|c|c|c|c|c|c|c|}
\hline $\begin{array}{c}\text { Estação } \\
\text { Meteorológica }\end{array}$ & Jan. & Fev. & Mar. & Abr. & Maio & Jun. & $\begin{array}{l}2002 \\
\text { Jul. }\end{array}$ & Ago. & Set. & Out. & Nov & Dez. & Total \\
\hline Bom Jesus & 178,7 & 137,9 & 103,4 & 127,4 & 109,5 & 263,8 & 137,9 & 158,2 & 172,9 & 278,1 & 174,3 & 180,9 & 2023,0 \\
\hline Caxias do Sul & 159,0 & 119,3 & 138,0 & 157,2 & 130,7 & 244,9 & 184,9 & 175,5 & 160,6 & 302,9 & 204,2 & 248,0 & 2225,2 \\
\hline Encruzilhada & 120,7 & 128,0 & 230,1 & 227,1 & 174,5 & 257,6 & 274,8 & 188,2 & 225,8 & 282,0 & 193,5 & 320,6 & 2622,9 \\
\hline Iraí & 113,8 & 56,0 & 85,1 & 51,0 & 197,8 & 179,8 & 94,1 & 144,7 & 138,9 & 395,3 & 205,2 & 284,0 & 1945,7 \\
\hline Passo Fundo & 96,0 & 76,7 & 356,8 & 135,9 & 140,4 & 219,0 & 146,3 & 233,8 & 253,6 & 372,3 & 205,0 & 329,5 & 2565,3 \\
\hline Santa Maria & 111,8 & 101,2 & 252,1 & 183,7 & 204,6 & 175,1 & 238,3 & 283,8 & 306,8 & 349,8 & 243,4 & 232,8 & 2683,4 \\
\hline Santa V. Palmar & 123,9 & 191,1 & 473,5 & 229,9 & 91,9 & 87,2 & 120,9 & 209,3 & 42,0 & 66,4 & 72,5 & 202,6 & 1911,2 \\
\hline Uruguaiana & 100,3 & 51,4 & 358,1 & 336,8 & 84,4 & 39,9 & 132,7 & 69,7 & 140,0 & 246,2 & 169,3 & 277,4 & 2006,2 \\
\hline
\end{tabular}

Ao observar a figura 5, destaca-se que somente as regiões de Caxias do Sul e Bom Jesus não apresentaram déficit hídrico. Na maioria dos meses, destaca-se o excedente hídrico, superando em alguns meses mais de $100 \mathrm{~mm}$. Os meses de setembro, outubro e novembro registraram os maiores excedentes e valores mensais de precipitação. Tal período requer atenção com relação ao excesso de precipitação e umidade nas fases fenológicas da expansão foliar e da floração. Os totais pluviométricos registrados nesses dois locais para o ano chuvoso foram, respectivamente, $2.225,2 \mathrm{~mm}$ e $2.023,0 \mathrm{~mm}$. Segundo Sparks (2005), o efeito de umidade excessiva decorrente de chuvas prolongadas pode ser minimizado com locais de drenagem adequadas, ou seja, áreas preferencialmente em encostas do que as áreas planas, propícias a alagamentos.

Durante o período de floração e polinização da nogueira pecã, meses de outubro e novembro, somente Santa Vitória do Palmar registrou déficit hídrico de $6,2 \mathrm{~mm}$. Isso deve-se ao fato de ter apresentado os menores totais pluviométricos, dentre as estações analisadas, tanto em outubro $(66,4 \mathrm{~mm})$ quanto em novembro $(72,5 \mathrm{~mm})$. Além disso, apresentou o menor total pluviométrico anual, isto é, $1.911,2 \mathrm{~mm}$ para o ano em questão. Porém, ainda assim, apresentou um valor muito acima de sua média histórica que é de $1.230,6 \mathrm{~mm}$.

Nos meses de janeiro, fevereiro e março, que compreendem o desenvolvimento da amêndoa, do seu tamanho até a formação da casca, destaca-se o déficit hídrico nas regiões de Encruzilhada do Sul, Iraí, Passo Fundo, Santa Maria, Santa Vitória do Palmar e Uruguaiana, ou seja, em 75\% das regiões analisadas. Isso demonstra que, apesar dos totais pluviométricos anuais serem elevados, como é o caso de Santa Maria com o maior total $(2.683,4 \mathrm{~mm})$, a análise da variação espacial e temporal da precipitação é fundamental para identificar-se as necessidades hídricas do cultivo.

Destaque especial para a região de Iraí que apresentou o maior período de déficit hídrico, com valor superior a $20 \mathrm{~mm}$, desde janeiro até meados de maio, comprometendo quase que, na totalidade a formação e a maturação dos frutos. Além disso, o total pluviométrico registrado no ano em estudo foi inferior a sua média histórica de $1.953,3 \mathrm{~mm}$. Merece ênfase também Uruguaiana que apresentou os maiores déficit hídricos para os meses de janeiro $(-36,8 \mathrm{~mm})$ e 
fevereiro $(-32,4 \mathrm{~mm})$. Porém, em março, apresentou o maior total mensal pluviométrico 358,1 mm e um excedente hídrico de $178,6 \mathrm{~mm}$.

No período da colheita das nozes, em abril e maio, na maioria das regiões analisadas, com exceção de Iraí, houve excedente hídrico. Em março, período em que as nozes já se encontram bem formadas, a região de Santa Vitória do Palmar apresentou o maior excedente hídrico com valor superior a $250 \mathrm{~mm}$. Essa região destaca-se pelos valores máximos e mínimos registrados, ou seja, precipitação de 473,5 mm em março e $42 \mathrm{~mm}$ em setembro.

A figura 6 apresenta o balanço hídrico da cultura para o ano-padrão seco (2004) da série histórica, nas oito estações meteorológicas selecionadas.

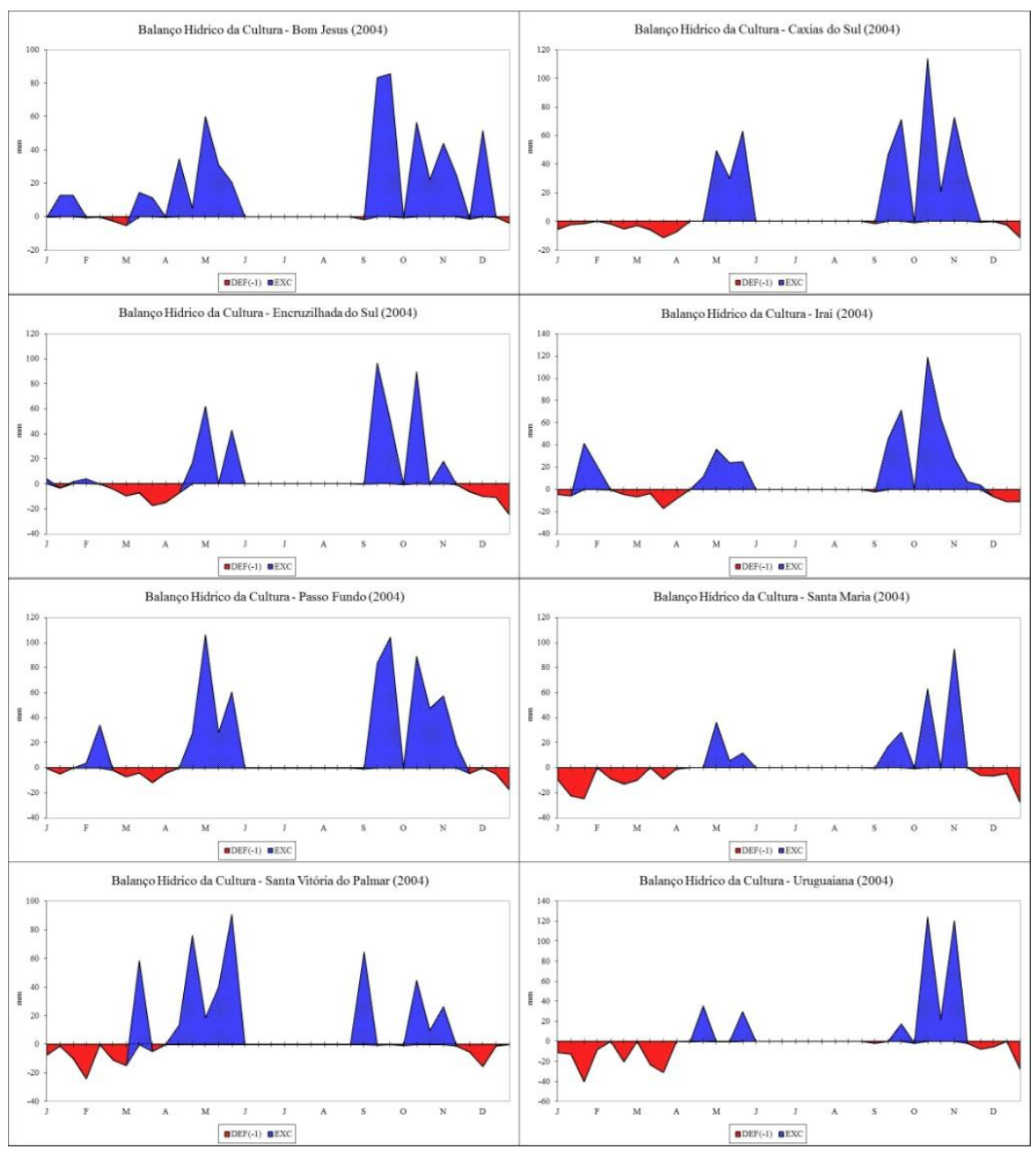

Figura 6 - Balanço hídrico da cultura para o ano-padrão seco (2004) da série histórica em Bom Jesus, Caxias do Sul, Encruzilhada do Sul, Iraí, Passo Fundo, Santa Maria, Santa Vitória do Palmar e Uruguaiana.

De acordo com os balanços hídricos da cultura apresentados na figura 6, verifica-se que os períodos de déficit hídrico intensificaram-se em diferentes meses do ano em todas as estações, ainda que se notem períodos significativos de excedente. Para melhor compreender a dinâmica desse ano, considerado seco, a tabela 3 apresenta a precipitação pluviométrica para o ano de 2004, mensal e total, das oito estações meteorológicas selecionadas. 
Tabela 3 - Precipitação pluviométrica do ano de 2004, mensal e total, em oito estações meteorológicas do Rio Grande do Sul.

\begin{tabular}{|c|c|c|c|c|c|c|c|c|c|c|c|c|c|}
\hline \multirow{2}{*}{$\begin{array}{c}\text { Estação } \\
\text { Meteorológica }\end{array}$} & \multicolumn{13}{|c|}{2004} \\
\hline & Jan. & Fev. & Mar. & Abr. & Maio & Jun. & Jul. & Ago. & Set. & Out. & Nov & Dez. & Total \\
\hline Bom Jesus & 124,2 & 52,5 & 114,4 & 92,8 & 137,3 & 31,3 & 129,2 & 34,0 & 213,2 & 126,2 & 115,6 & 127,4 & 1298,1 \\
\hline Caxias do Sul & 64,2 & 78,6 & 39,4 & 77,2 & 204,4 & 58,3 & 168,8 & 38,1 & 164,7 & 185,2 & 163,0 & 51,9 & 1293,8 \\
\hline Encruzilhada & 128,4 & 72,6 & 18,2 & 121,8 & 135,5 & 94,3 & 210,6 & 107,2 & 190,4 & 134,3 & 57,5 & 29,6 & 1300,4 \\
\hline Iraí & 176,4 & 99,0 & 44,1 & 138,5 & 116,1 & 55,0 & 173,0 & 35,3 & 171,0 & 250,5 & 131,0 & 56,2 & 1446,1 \\
\hline Passo Fundo & 97,5 & 123,0 & 26,7 & 142,3 & 222,4 & 133,5 & 88,8 & 53,0 & 234,3 & 193,2 & 121,9 & 67,3 & 1503,9 \\
\hline Santa Maria & 21,7 & 110,8 & 94,1 & 101,5 & 85,8 & 72,1 & 72,5 & 85,3 & 96,3 & 120,1 & 147,7 & 62,2 & 1070,1 \\
\hline Sant. V. Palmar & 62,7 & 49,6 & 172,1 & 178,0 & 181,5 & 75,3 & 80,7 & 62,1 & 99,5 & 107,0 & 59,7 & 77,7 & 1205,9 \\
\hline Uruguaiana & 21,7 & 98,1 & 40,7 & 186,0 & 53,6 & 85,4 & 57,9 & 21,7 & 61,2 & 206,9 & 157,3 & 79,6 & 1070,1 \\
\hline
\end{tabular}

No período de expansão foliar, nos meses de setembro e outubro, todas as regiões registraram excedente hídrico, com exceção de Uruguaiana, que apresentou déficit hídrico superior a $50 \mathrm{~mm}$. Destaca-se Passo Fundo que apresentou o maior total pluviométrico anual $(1.503,9 \mathrm{~mm})$ e também o maior total mensal para o mês de setembro $(234,3 \mathrm{~mm})$, resultando em um excedente hídrico superior a $100 \mathrm{~mm}$. O excedente hídrico no período pode estar associado com períodos de umidade e precipitações consecutivas que favorecem o ataque por patógenos. De outubro até meados de novembro, também foram registrados excedentes hídricos em todas as regiões analisadas, período que compreende a floração e a polinização.

A formação das nozes que tem início ao final do mês de novembro prolongando-se até meados de março requer índices de precipitações adequadas, para que ocorra um bom desenvolvimento dos frutos (tamanho, coloração, óleo). No ano em análise, o mês de dezembro apresentou déficit hídrico em todas as regiões analisadas e se forem analisados os totais mensais para esse mês, comprova-se que a precipitação foi muito inferior aos outros meses. Destacam-se Encruzilhada do Sul e Santa Maria que apresentaram déficit hídricos superiores a $20 \mathrm{~mm}$ e precipitações mensais em dezembro de 29,6 e $62,2 \mathrm{~mm}$, respectivamente.

Os meses de janeiro, fevereiro e março destacam-se por apresentar predomínio de déficit hídrico com algumas variações de excedentes. As regiões de Uruguaiana, Santa Maria e Caxias do Sul apresentaram déficit hídrico durante todo o período de formação das nozes, registrando valores durante esses três meses de $-147,7 \mathrm{~mm},-97,8 \mathrm{~mm}$ e $-37 \mathrm{~mm}$. Uruguaiana e Santa Maria destacam-se por apresentar os menores totais pluviométricos anuais de $1.070,1$ $\mathrm{mm}$ e Caxias do Sul de 1.293,8 mm. Além disso, Uruguaiana e Santa Maria registraram totais pluviométricos para janeiro de apenas $21,7 \mathrm{~mm}$ em ambos. Para as três regiões, a precipitação total no ano seco foi significativa, isto é, abaixo da média histórica que é de $1.407,1 \mathrm{~mm}$ para Uruguaiana, $1.736,1$ para Santa Maria e $1.774,9 \mathrm{~mm}$ para Caxias do Sul.

As regiões de Bom Jesus, Iraí, Encruzilhada do Sul, Passo Fundo e Santa Vitória do Palmar também apresentaram déficit hídrico no período de desenvolvimento das nozes, com pequenos intervalos de excedente. Santa Vitória do Palmar apresentou o maior déficit hídrico no mês de fevereiro $(-34,8$ 
$\mathrm{mm}$ ), com apenas 49,6 $\mathrm{mm}$ para esse mesmo mês, seguida da região de Encruzilhada do Sul que registrou, no mês de março, o menor total pluviométrico de todas as estações, $18,2 \mathrm{~mm}$ e um déficit hídrico de $-34 \mathrm{~mm}$.

De acordo com Sparks (1997), as precipitações inadequadas durante o período de desenvolvimento das nozes poderão interferir na sua qualidade. Segundo o autor, a falta de precipitação no início da formação das nozes pode resultar em nozes pequenas, mas se houver um período sequente de precipitação adequada, o tamanho das nozes poderá ser normal. Além disso, as nozes poderão ser grandes, mas mal preenchidas, sob condição de umidade do solo adequada durante o alongamento e a expansão das nozes (finais de novembro a primeira quinzena de janeiro), seguido de umidade inadequada durante o desenvolvimento da amêndoa (a partir da metade de janeiro até meados de março).

No estudo desenvolvido por Vidal e Pintos (2013), verificou-se caída de flores nos meados de novembro e uma queda significativa de frutos nos finais de janeiro e início de fevereiro, prolongando-se até finais de março. Segundo os autores, as flores estavam mal formadas ou não polinizadas e as nozes eram pequenas. O aborto do embrião pode estar associado ao rápido incremento de peso da amêndoa, o que implicaria em questões nutricionais entre os frutos e as folhas (SPARKS, 1995). A queda dos frutos, que atingiu cerca de $50 \%$ do potencial produtivo, foi relacionada ao déficit hídrico registrado nesse período.

No período de colheita das nozes, meses de abril e maio, as regiões em análise apresentaram variações com excedente e déficit hídrico. Destacam-se as regiões de Bom Jesus, Passo Fundo e Santa Vitória do Palmar que apresentaram excedentes hídricos significativos superiores a $60 \mathrm{~mm}, 100 \mathrm{~mm}$ e $80 \mathrm{~mm}$, respectivamente. Esses excedentes são decorrentes das precipitações mensais registradas nesses dois meses que superaram os $100 \mathrm{~mm}$, com exceção apenas para o mês de abril, em Bom Jesus, que registrou 92,8 $\mathrm{mm}$.

A análise desses balanços hídricos demonstra que, de fato, o ano seco dessa série histórica, implicaria déficit hídrico em todas as regiões do Estado, especialmente no período de formação das nozes de janeiro a março, com destaque para as regiões de Uruguaiana, Santa Maria e Santa Vitória do Palmar. As precipitações inadequadas nesse período, como já destacado anteriormente, implicam, sobretudo, a qualidade das nozes e, consequentemente, o rendimento produtivo.

Dessa forma, como notou-se na variabilidade de chuvas nos anos de 2002 (ano chuvoso) e 2004 (ano seco), a presença tanto de déficit como de excedente hídrico, pode-se afirmar que o espaço geográfico em estudo está mais propenso a condições de excedentes hídricos do que déficit. A partir da variabilidade espaço-temporal da precipitação em questão, quanto da temperatura, bem como de outros fenômenos naturais, é importante salientar que o homem exerce pouco controle sobre as mesmas. Assim, em casos de déficit hídrico ou de excedentes é necessário desenvolver um bom manejo do cultivo, tentando minimizar ao máximo a interferência deles sobre a produção.

Em condições de secas muito severas, Sparks (2009) relata que a seca afeta a fruta muito cedo, causando a supressão do seu crescimento, pelo menos três semanas após a polinização. Segundo o autor, a umidade armazenada no perfil do solo pelas chuvas do inverno não é suficiente para suprir as 
necessidades da nogueira na primavera, nas condições climáticas encontradas na Geórgia. Nesse caso, o autor indica que a gestão da irrigação para o crescimento dos frutos deve iniciar ainda na polinização. Porém, se a seca já estiver suprimindo a sessão de diâmetro, a irrigação para crescimento da parte aérea deve iniciar antes ou durante a brotação, dependendo da gravidade da seca (SPARKS, 2009).

A figura 7 apresentam o balanço hídrico da cultura para o ano-padrão habitual (2013), nas oito estações meteorológicas selecionadas.

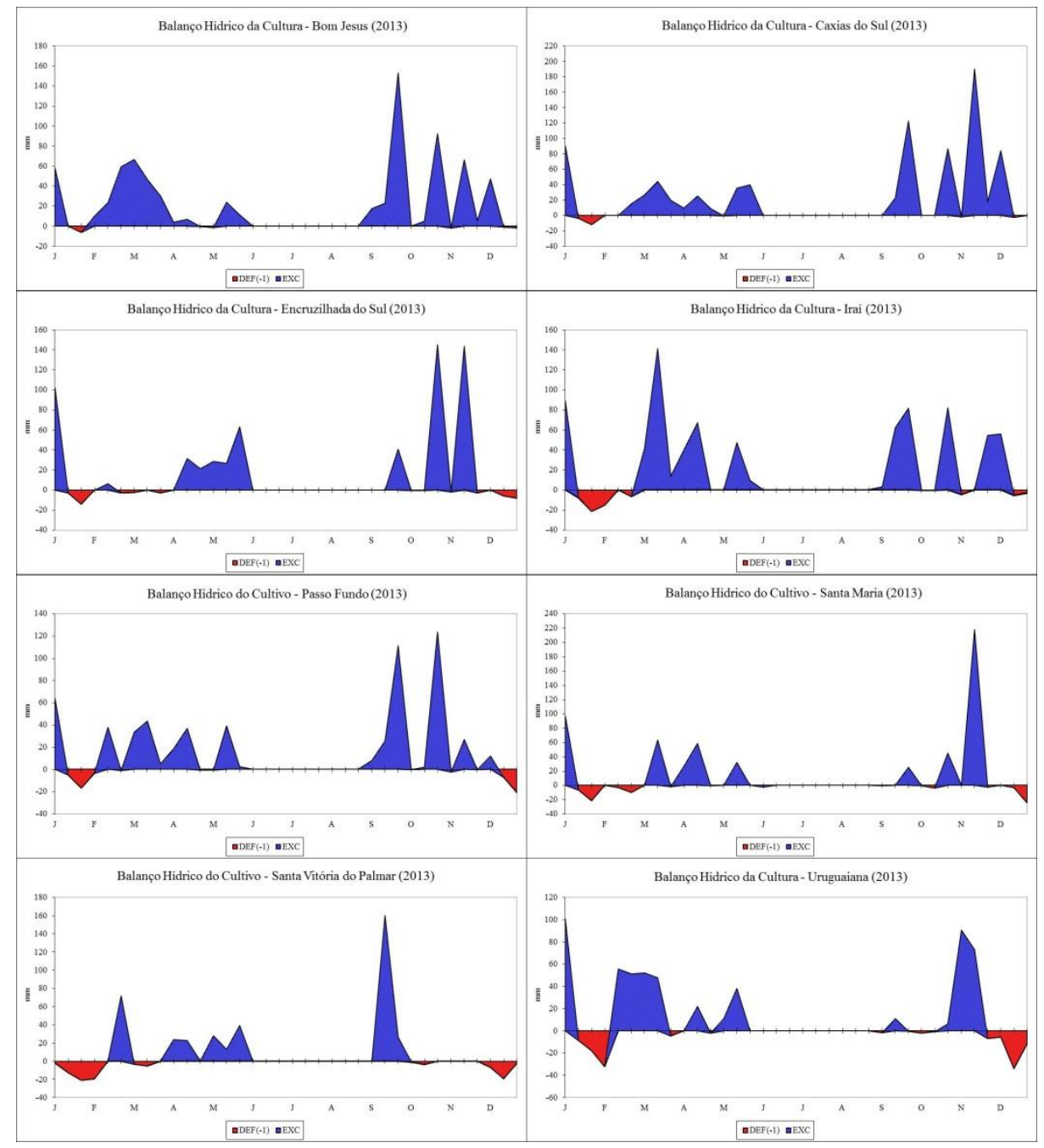

Figura 7 - Balanço hídrico da cultura para o ano-padrão habitual (2013) da série histórica em Bom Jesus, Caxias do Sul, Encruzilhada do Sul, Iraí, Passo Fundo, Santa Maria, Santa Vitória do Palmar e Uruguaiana.

No ano-padrão habitual de 2013, que representa o ano com totais pluviométricos mais próximos da média histórica, pode-se verificar que as regiões selecionadas apresentaram períodos de déficit hídrico, principalmente de janeiro a março e em dezembro. Os excessos concentraram-se principalmente a partir do mês de abril até novembro. A tabela 4 apresenta a precipitação pluviométrica do ano de 2013, mensal e total, das oito estações meteorológicas 
selecionadas e possibilitará compreender melhor o balanço hídrico para esse ano.

Tabela 4 - Precipitação pluviométrica do ano de 2013, mensal e total, em oito estações meteorológicas do Rio Grande do Sul.

\begin{tabular}{lrrrrrrrrrrrrr}
\hline $\begin{array}{c}\text { Estação } \\
\text { Meteorológica }\end{array}$ & Jan. & Fev. & Mar. & Abr. & Maio & Jun. & \multicolumn{1}{c}{ Jul. } & Ago. & Set. & Out. & Nov & Dez. & Total \\
\hline Bom Jesus & 116,1 & 212,1 & 211,1 & 45,4 & 75,3 & 136,4 & 98,4 & $\mathbf{4 1 5 , 5}$ & 232,1 & 148,7 & 142,4 & 131,2 & 1964,7 \\
Caxias do Sul & 131,6 & 157,3 & 159,9 & 93,3 & 110,8 & 144,9 & 82,3 & 373,6 & 186,2 & 140,5 & 284,9 & 185,2 & $\mathbf{2 0 5 0 , 5}$ \\
Encruzilhada & 155,4 & 133,2 & 70,5 & 129,2 & 151,6 & 89,9 & 95,3 & 181,9 & 80,3 & 200,9 & 198,4 & 99,3 & 1585,9 \\
Iraín & 146,6 & 126,2 & 316,8 & 152,5 & 98,8 & 210,1 & 44,4 & 212,9 & 191,6 & 157,7 & 159,1 & 164,0 & 1980,7 \\
Passo Fundo & 101,8 & 170,5 & 165,9 & 95,7 & 85,2 & 127,6 & 81,4 & 363,6 & 184,0 & 186,4 & 103,9 & 66,4 & 1732,4 \\
Santa Maria & 145,3 & 97,7 & 188,6 & 147,4 & 71,6 & 81,6 & 113,5 & 163,8 & 69,2 & 108,7 & 294,5 & 92,8 & 1574,7 \\
Sant. V. Palmar & 27,5 & 222,0 & 52,3 & 111,7 & 113,9 & 33,2 & 90,5 & 114,9 & 223,8 & 29,3 & 88,6 & 59,7 & $\mathbf{1 1 6 7 , 4}$ \\
Uruguaiana & 163,4 & 257,7 & 155,4 & 84,4 & 101,4 & 25,8 & 102,4 & $\mathbf{2 3 , 1}$ & 42,5 & 85,1 & 225,1 & 89,9 & 1356,2 \\
\hline
\end{tabular}

É importante destacar que, no ano de 2013, considerado ano habitual, as variações pluviométricas são significativas, quando observam-se os totais mensais na tabela 4. Entre os meses de março a julho, de forma alternada, as regiões em análise apresentaram totais pluviométricos mensais abaixo de 30 $\mathrm{mm}$, ainda que, este seja o período de menores requerimentos para a nogueira pecã. Dá-se ênfase para o mês de agosto que, após baixa precipitação em julho, registrou um aumento na precipitação em sete das oito regiões. A exceção foi Uruguaiana, que, no mesmo mês, apresentou o menor total mensal de todo o período, ou seja, apenas $23,1 \mathrm{~mm}$.

Ao observar a figura 7 , verifica-se que, após o período de dormência, isto é, meses de junho, julho e agosto, no inverno, a maioria das regiões registrou excedentes hídricos significativos, tais como Bom Jesus e Santa Vitória do Palmar, com mais de $160 \mathrm{~mm}$. Essas duas regiões destacam-se também por apresentarem os maiores totais pluviométricos mensais para o mês de setembro, período da expansão foliar da nogueira pecã, em que Bom Jesus registrou 232,1 mm e Santa Vitória do Palmar, 223,8 mm. Além disso, Bom Jesus apresentou o maior total pluviométrico mensal, dentre as regiões analisadas, para o mês de agosto com 415,5 mm.

Durante a expansão foliar, nos meses de setembro e outubro, todas as regiões registraram excedente hídrico, especialmente Bom Jesus, Caxias do Sul, Passo Fundo e Santa Vitória do Palmar. Nos meses de outubro e novembro, durante a floração e o término da expansão foliar, a maioria das regiões apresentou excedentes hídricos significativos, tais como Santa Maria com mais de $220 \mathrm{~mm}$, Caxias do Sul, mais de $180 \mathrm{~mm}$, Encruzilhada do Sul, mais de 140 $\mathrm{mm}$, Passo Fundo, superior a $120 \mathrm{~mm}$ e Bom Jesus, Uruguaiana e Iraí, com excedentes superiores a $80 \mathrm{~mm}$. Santa Vitória do Palmar destaca-se por não apresentar excedente hídrico para esse período e um déficit de $-4,7 \mathrm{~mm}$ em outubro, registrando somente 29,3 mm para esse mês. Essa região apresentou também o menor pluviométrico anual $1.167,4 \mathrm{~mm}$, um pouco abaixo de sua média histórica de 1.230,6 mm.

Em dezembro, quando as nozes já iniciaram a sua formação e requerem pluviosidade adequada para o seu bom desenvolvimento, destaca-se o déficit 
hídrico em seis das oito regiões analisadas. A região de Uruguaiana merece ênfase por apresentar o maior déficit hídrico $(-57,6 \mathrm{~mm})$, seguida de Santa Vitória do Palmar $(-28,8 \mathrm{~mm})$ e Passo Fundo $(-28,2 \mathrm{~mm})$. O total pluviométrico para dezembro nessas três regiões foi, respectivamente, $89,9 \mathrm{~mm}, 59,7 \mathrm{~mm}$ e $66,4 \mathrm{~mm}$. Essas variações de déficit ou excesso hídrico não se devem somente à pluviosidade, mas também à interferência da temperatura média e da latitude, variáveis consideradas no balanço hídrico. Ainda nesse mês, destacam-se as regiões de Bom Jesus e Caxias do Sul que não apresentaram déficit hídrico. Caxias do Sul, por sua vez, é a região que apresentou o maior total pluviométrico anual $(2.050,5 \mathrm{~mm})$, dentre as estações analisadas.

Nos meses sequentes à formação dos frutos, de janeiro a março, destacam-se períodos de déficit hídrico intercalados com excedentes, o que pode não ser tão prejudicial à nogueira pecã. As regiões que mais se destacaram pelo déficit hídrico foram Santa Vitória do Palmar (-64,0 mm), Uruguaiana $(-63,6 \mathrm{~mm})$, Iraí $(-52,4 \mathrm{~mm})$ e Santa Maria $(-44,8 \mathrm{~mm})$.

Desta forma, quando da implantação ou condução de um pomar de nogueiras pecã deve-se atentar para as condições climáticas da região geográfica, pois, o clima também desempenha um papel significativo na gestão de pragas do cultivo conforme destacam Reid e Hunt (2000). Além disso, devese observar os anos que estiverem sob a influência dos fenômenos El Niño e La Niña, principalmente quando a expectativa de chuva é abaixo ou acima do normal. Recomenda-se, na implantação de um pomar, observar uma densidade de árvores que esteja de acordo com o tipo de solo e condições climáticas do local, implantar um sistema de irrigação se a área a ser cultivada possuiu um histórico de estiagens, especialmente atentando para os períodos críticos da nogueira e manter uma boa cobertura do solo por meio do manejo de forrageiras e pastagens.

\section{CONCLUSÕES}

O estudo e análise da precipitação pluviométrica e sua relação com os cultivos agrícolas é de fundamental importância. A variabilidade diária e/ou mensal dos dados climáticos pode influenciar nas diferentes fases fenológicas dos cultivos. No Rio Grande do Sul, onde a nogueira pecã é cultivada, a precipitação pluviométrica é $1.651 \mathrm{~mm}$ anuais e variou espacialmente de 1.200 $\mathrm{mm}$ a $2.000 \mathrm{~mm}$. O ano de 2013 foi considerado o ano-padrão habitual (1.657 $\mathrm{mm})$, o ano de 2002, chuvoso $(2.201 \mathrm{~mm})$ e 2004, o ano seco $(1.307 \mathrm{~mm})$.

Em 2002 a análise do balanço hídrico do cultivo apresentou, na maioria das estações meteorológicas, excesso hídrico nos meses de setembro a dezembro, período de floração e formação dos frutos. No ano de 2004, ano seco, destacam-se as ocorrências de déficit hídrico, no crescimento das nozes e na colheita, isto é, de janeiro a abril. No ano de 2013, ano habitual, constataram-se períodos de excedente hídrico alternados de déficit para todas as estações em análise. Desta forma, evidencia-se que o cultivo da nogueira pecã tem potencial para o desenvolvimento no Estado, porém, antes da implantação de um pomar recomenda-se avaliar as condições edafoclimáticas específicas do local. 


\section{AGRADECIMENTOS}

Agradecemos à FAPERGS (Fundação de Amparo à Pesquisa do Estado do Rio Grande do Sul) e à CAPES (Coordenação de Aperfeiçoamento de Pessoal de Nível Superior) pela bolsa de doutorado, e ao CNPq (Conselho Nacional de Desenvolvimento Científico e Tecnológico) pela bolsa de doutorado sanduíche da primeira autora (Processo no 200592/2014-9).

\section{REFERÊNCIAS BIBLIOGRÁFICAS}

ALVARES, C. A. et al. Köppen's climate classification map for Brazil. Meteorologische Zeitschrift. Stuttgart, v. 22, n. 6, p. 711-728, 2013.

DIAS, H. E. Necesidades hídricas y riego del pecán. In: LAVADO, R. S.; FRUSSO, E. A. (Org.). Producción de pecán en Argentina. Buenos Aires: [s.n], 2007. p. 121.

FRUSSO, E. A. Características morfológicas y fenológicas del pecán. In: LAVADO, R. S.; FRUSSO, E. A. (Org.). Producción de pecán en Argentina. Buenos Aires: [s.n], 2007. p. 1 - 18.

GONÇALVES, M. B.; SENTELHAS, P. C. Zoneamento agroclimático para a cultura do pinhão manso no estado da Bahia, objetivando a produção de bicombustível. Prêmio Mercosul de Ciência e Tecnologia. Brasília, 2008, p. 121 - 140.

GRAGEDA, J. G. et al., El clima y la producción de nogal pecanero. In: XIV SIMPOSIO INTERNACIONAL DE NOGAL PECANEIRO, 2013, México. Anais... México: Instituto Nacional de Investigaciones Forestales, Agrícolas y Pecuarias, 2013, p. 55-66.

MADERO, E. R.; FRUSSO, E. A.; BRUNO, N. R. Desarrollo del cultivo de la nuez pecan en la Argentina. ProPecan. Argentina: INTA, 2012.

MADERO, E.; FRUSSO, E. A.; CASAUBON, E. Manejo del cultivo. In: LAVADO, R. S.; FRUSSO, E. A. (Org.). Producción de pecán en Argentina. Buenos Aires: [s.n], 2007. p. 1-27.

MOHLENBROCK, R. Peca - Carya illinoinensis (Wangenh.) K. Koch. Plant Guide. Lousiana: USDA, 2003.

MONTEIRO, A. et al. Atlas da saúde e da doença: Vulnerabilidades Climáticas e Socioeconómicas. Volume II. Porto, Portugal, 2012.

MOTA; F. S. da; ZAHLER, P. J. M. Clima, agricultura e pecuária no Rio Grande do Sul. Pelotas: Livraria Mundial, 1994.

MOURA, M. de O.; ZANELLA, M. E. Escolha de "anos- padrão" para o estudo do conforto térmico em Fortaleza, CE: verificação de critérios. Revista GEONORTE, v. 1, n. 2, p. 547-560, 2012.

ORGANIZAÇÃO METEOROLÓGICA MUNDIAL. World Climate Programme Data: calculation of monthly and annual 30-years standard normals. WMO-TD/NO 341 . Washington: WMO, 1989.

PAIVA, P. Saiba como os fenômenos El Niño e La Niña afetam a agricultura brasileira. Reportagem. Canal Rural: São Paulo, 14 de maio de 2015. Disponível 
em: <http://www.canalrural.com.br/noticias/tempo/saiba-como-fenomenosnino-nina-afetam-agricultura-brasileira-8929>. Acesso em: 16 set. 2015.

PEREIRA, A. R., ANGELOCCI, L. R. SENTELHAS, P. C. Agrometeorologia: fundamentos e aplicações práticas. Guaíba: Agropecuária, 2002.

PETERSON, J. K. Pecan - Carya illinoensis (Wangenh.) K. Koch. Volume 2: Hardwoods. Silvics of North America. 1990. Disponível em: < http://www.na.fs.fed.us/pubs/silvics_manual/volume_2/carya/illinoesis.htm >. Acesso em 30 jun. 2014.

REID, W.; HUNT, K. L. Pecan Production in the Northern United States. HortTechnology. v. 10, n. 2, p. 298 - 301, abr./jun, 2000.

ROLIM, G. DE S.; SENTELHAS, P. C. Balanço Hídrico Sequencial por Thornthwaite \& Wather (1955). Planilha do Excel. 2002. Disponível em: < www.Ice.esalq.usp.br/angelocci/BHseq63.xls>. Acesso em: 04. nov. 2014.

ROSSATO, M; S. Os Climas do Rio Grande do Sul: variabilidade, tendências e tipologias. 2011. 240 f. Tese (Doutorado em Geografia) - Universidade Federal do Rio Grande do Sul - Instituto de Geociências. Porto Alegre, 2011.

SAMMIS, T. W.; MEXAL, J. G.; MILLER, D. Evapotranspiration of flood-irrigated pecans. Agricultural Water Management. Amsterdam, v. 69, n. 3, p. 179-190, 2004.

SANT'ANNA NETO, J. L. As chuvas no estado de São Paulo: contribuição ao estudo da variabilidade e tendência da pluviosidade na perspectiva da análise geográfica. 1995. 202f. Tese (Doutorado em Geografia) Faculdade de Filosofia, Letras e Ciências Humanas, Universidade de São Paulo, São Paulo.

SARTORI, M. da G. B. A circulação atmosférica regional e os principais tipos de sucessão do tempo no inverno do Rio Grande do Sul, Brasil. Ciência e Natura. Santa Maria, v. 1, n. 15, p. 69-93, 1993.

SARTORI, M. da G. B. A dinâmica do clima do Rio Grande do Sul: indução empírica e conhecimento científico. Revista Terra Livre. São Paulo, v. 1, n. 20, p. 27-49, jan/jul. 2003.

SIERRA, E. M.; LÓPEZ, E. L.; PÉREZ, S. P. Agroclimatología del pecán (Carya illinoinensis) en la Argentina. In: LAVADO, R. S.; FRUSSO, E. A. (Org.). Producción de pecán en Argentina. Buenos Aires: [s.n], 2007. p. 1-10

SILVESTRE, M. R.; SANT'ANNA NETO, J. L.; FLORES, E. F. Critérios estatísticos para definir anos-padrão: uma contribuição à climatologia geográfica. Revista Formação, v. 20, n. 2, p. 23-53, 2013.

SPARKS, D. A. A Climatic approach to pecan scab control. HortTechnology. v. 5, n. 3, p. 225 - 230, 1995.

SPARKS, D. A. A Climatic Model for Pecan Production under Humid Conditions. Journal of the American Society Horticultural Science. Georgia, v. 121, n. 5, p. $908-914,1996$.

SPARKS, D. A. A climatic model for predicting Georgia's pecan production. Proc. S. E. Pecan Growers Assn. v. 90, p. 32 - 44, 1997.

SPARKS, D. A. Adaptability of Pecan as a Species. HortScience. Georgia, v. 40, n. 5 , p. $1175-1189,2005$. 
SPARKS, D. A. Drought Damages Pecan During the Early Stage of Fruit Development. 2009.

Disponível

em: <http://www.oocities.org/pecan_man1/drought.htm>. Acesso em: 14 jul. 2014. THORNTHWAITE, C. W.; WATHER, J. R. The water balance. Drexel Institute of Technology. Laboratory of Climatology. Publications in Climatology. v. VIII, n. 1, 1955.

VALDEZ, G. B.; DURÓN, N. L. Programación del riego en Nogal. In: SEMINARIO INTERNACIONAL DE NOGAL PECANERO. México: INIFAP. Anais... 2009, p. 37 47.

VIDAL, V. T.; PINTOS, V. V. G. Caracterización de la nuez pecan "Carya illinoinensis" y sus perspectivas de comercialización en el Uruguay. Monografia (Faculdad de Agronomia) - Universidad de la Republica, Montevideo, 2013. 